INF. \& ANN.

\title{
Science Academies' Refresher Course on Quantum Mechanics
}

\author{
5 - 18 May 2014 \\ Sponsored by Indian Academy of Sciences, Bangalore, \\ Indian National Science Academy, NewDelhi \\ The National Academy of Sciences, India, Allahabad \\ In collaboration with Bishop Moore College, Mavelikara, Kerala
}

\begin{abstract}
A Refresher Course in 'Quantum Mechanics' for College/University teachers/research scholars will be held at the Post-Graduate and Research Department of Physics, Bishop Moore College, Mavelikara, Kerala, during 5-18 May, 2014. The Course is primarily aimed at teachers involved in teaching quantum mechanics at the UG/PG level although a few seats will be available for research scholars in physics. The Course will cover the basic and advanced topics of quantum mechanics, through lectures and tutorials. College/University teachers having at least a Master's degree in Physics are particularly encouraged to apply.
\end{abstract}

Topics: Most of the topics in a standard UG/PG level course syllabus will be covered. There will be four modules:

Module 1: Formulation, Schrödinger equation, angular momentum, H-atom;

Module 2: Scattering, time-independent perturbations, WKB, variational method;

Module 3: Symmetries and conservation laws, Klein-Gordon and Dirac equations;

Module 4: Time-dependent perturbation, field quantization.

Resource Persons:

Professors M Lakshmanan (Centre for Nonlinear Dynamics, Bharathidasan University, Tiruchirapalli), H S Mani (Chennai Mathematical Institute), G Rajasekaran (The Institute of Mathematical Sciences and Chennai Mathematical Institute) and Govind Krishnaswami (Chennai Mathematical Institute).

Course Director: Professor M Lakshmanan; Course Coordinator: Dr D Sajan

Teachers/research scholars who wish to participate should send their applications online using the following link. http://web-japps.ias.ac.in:8080/Refreshcourse/BMC2014.jsp

A printed copy of the application through the Head of the institution should be sent by speed post to: Prof. M Lakshmanan, Centre for Nonlinear Dynamics, Bharathidasan University, Tiruchirapalli 620 024, India. For any further query, please e-mail to: lakshman.cnld@gmail.com. Please note that participants have to attend the full duration of the Course.

Last date for receipt of applications: 15 February 2014.

RESONANCE | December 2013 